\title{
MicroRNA-224 sustains Wnt/ $\beta$-catenin signaling and promotes aggressive phenotype of colorectal cancer
}

\author{
Tingting $\mathrm{Li}^{1,2,3 \dagger}$, Qiuhua Lai ${ }^{1,2,3 \dagger}$, Shuyang Wang ${ }^{1,2,3}$, Juanjuan Cai ${ }^{1,2,3}$, Zhiyuan Xiao ${ }^{1,2,3}$, Danling Deng ${ }^{1,2,3}$, \\ Liuqing He $\mathrm{He}^{1,2,3}$, Hongli Jiao ${ }^{1,2,3}$, Yaping Ye $\mathrm{e}^{1,2,3}$, Li Liang ${ }^{1,2,3}$, Yanqing Ding ${ }^{1,2,3}$ and Wenting Liao ${ }^{1,2,3^{*}}$
}

\begin{abstract}
Background: Growing evidence suggests that Wnt/ $\beta$-catenin pathway plays an important role in CRC development, progression and metastasis. Aberrant miR-224 expression has been reported in CRC. However, the mechanism of miR-224 promotes both proliferation and metastatic ability largely remains unclear.

Methods: Real-time PCR was used to quantify miR-224 expression. Luciferase reporter assays were conducted to confirm the activity of Wnt/ $\beta$-catenin pathway and target gene associations, and immunofluorescence staining assay was performed to observe the nuclear translocation of $\beta$-catenin. Bioinformatics analysis combined with in vivo and vitro functional assays showed the potential target genes, GSK3 $\beta$ and SFRP2, of miR-224. Specimens from forty patients with CRC were analyzed for the expression of miR-224 and the relationship with GSK3 $\beta / S F R P 2$ by real-time PCR and western blot.

Results: Bioinformatics and cell luciferase function studies verified the direct regulation of miR-224 on the 3'-UTR of the GSK3 $\beta$ and SFRP2 genes, which leads to the activation of Wnt/ $\beta$-catenin signaling and the nuclear translocation of $\beta$-catenin. In addition, knockdown of miR-224 significantly recovered the expression of GSK3 $\beta$ and SFRP2 and attenuated Wnt/ $\beta$-catenin-mediated cell metastasis and proliferation. The ectopic upregulation of miR-224 dramatically inhibited the expression of GSK3B/SFRP2 and enhanced CRC proliferation and invasion.
\end{abstract}

Conclusion: Our research showed mechanistic links between miR-224 and Wnt/ $\beta$-catenin in the pathogenesis of CRC through modulation of GSK3 $\beta$ and SFRP2.

Keywords: miR-224, Proliferation, Invasion, Colorectal cancer, Wnt/ß-catenin, GSK3ß, SFRP2

\section{Background}

Human colorectal cancer (CRC) is one of the most common types of malignant tumor worldwide [1]. Although several kinds of treatment modalities have been developed recently for the patients with CRC, the clinical outcome of prognosis continues to be poor in patients with advanced CRC. Metastasis is responsible for the majority of cancer deaths. The aberrant activation of Wnt/ $\beta$-catenin signaling pathway is considered to be an essential

\footnotetext{
* Correspondence: liaowt2002@gmail.com

${ }^{\dagger}$ Equal contributors

'Department of Pathology, Nanfang Hospital, Southern Medical University, Guangzhou 510515, Guangdong, China

${ }^{2}$ Department of Pathology, School of Basic Medical Sciences, Southern

Medical University, Guangzhou, Guangdong, China

Full list of author information is available at the end of the article
}

issue in tumorigenesis and progression of CRC $[2,3]$. The hallmark of the Wnt/ $\beta$-catenin pathway is the accumulation and nuclear localization of $\beta$-catenin $[4,5]$. Cytoplasmic $\beta$-catenin is controlled by the degradation complex composed of adenomatosis polyposis coli (APC), Axin, protein phosphatase 2A (PP2A), glycogen synthase kinase 3 beta (GSK3 $\beta$ ) and casein kinase $1 \alpha$ $(C K 1 \alpha)$ [6-9]. When Wnt signaling is activated, $\beta$ catenin is discharged from the degradation of complex resulting in the translocation of $\beta$-catenin into nucleus, where it associates with the T-cell factor/lymphoid enhancer factor (TCF/LEF) family of transcription factors to activate specific Wnt target genes $[10,11]$. It has been well known that inactivating mutation of APC gene has been considered to be an crucial event for 
constitutive activation of $\mathrm{Wnt} / \beta$-catenin signaling mutation which leads to carcinogenesis and progression in CRC $[12,13]$. However, it has been reported that the mutation of APC cannot fully explain the reason of colorectal tumor carcinogenesis $[14,15]$. Thus, alternative mechanisms through which $\mathrm{Wnt} / \beta$-catenin signaling were activated in CRC might exist.

MicroRNAs (miRNAs) are a class of noncoding small RNAs that play essential roles in the modulation of various biological processes through directly binding to the 3 ' untranslated region (3'-UTR) of target genes, which resulting in posttranscriptional inhibition and mRNA cleavage $[16,17]$. Accumulating evidence has indicated that dysregulation of miRNAs is closely related to the development and progression of CRC $[18,19]$. For example, MicroRNA-30b can function as a tumor suppressor in human colorectal cancer by targeting KRAS, PIK3CD and BCL2 [20]. Also, our previous study has demonstrated that miR-224 can promote cell proliferation by repressing PHLPP1 and PHLPP2 in CRC [21].

In this study, we displayed the critical role of miR-224 in activating $W n t / \beta$-catenin signaling pathway during colorectal progression. We showed that promotion effect of miR-224 on proliferation and invasion of human CRC cells could be manifested partly through the accumulation and nuclear translocation of $\beta$-catenin and subsequently up-regulation of its transcriptional targets c-Myc [22, 23] and CyclinD1 [24, 25]. Moreover, we demonstrated that both of $\mathrm{Wnt} / \beta$-catenin signaling pathway suppressors GSK3 $\beta$ and SFRP2 are bona fide downstream targets of miR-224.

\section{Methods}

\section{Tissue specimens and cell cultures}

The 40 freshly collected CRC specimens and their matched adjacent peri-cancerous normal tissues and distantly metastasis tissues were collected at the operation room, Nanfang Hospital. The fresh specimens were frozen and stored in liquid nitrogen until further use. For the use of clinical materials for research purposes, prior approval was obtained from the Southern Medical University Institutional Board (Guangzhou, China). All samples were collected and analyzed with the prior written, informed consent of the patients.

Two human CRC lines SW480 and HCT116 were purchased from American Type Culture Collection Cell Biology Collection and were maintained in Department of Pathology, Southern Medical University. SW480 and HCT 116 cell lines were cultured in RPMI 1640 (Invitrogen, Carlsbad, CA, USA). All medium was supplemented with $10 \%$ FBS (PAA Laboratories, Pasching, Austria) and $1 \%$ penicillin/streptomycin (Invitrogen) at $37{ }^{\circ} \mathrm{C}$ with $5 \% \mathrm{CO} 2$.
RNA isolation, reverse transcription (RT) and real-time PCR Total RNA from cultured cells and fresh surgical CRC tissues was isolated using the mirVana miRNA Isolation Kit (Ambion) according to the manufacturer's instruction. The cDNA was then synthesized from total RNA using the Taqman miRNA reverse transcription kit (Applied Biosystems, Foster City, CA, USA). Real-time PCR was performed with the Applied Biosystems 7500 Sequence Detection system, using $\mathrm{iQ}^{\mathrm{mi}}$ SYBR Green Supermix (BioRad Laboratories, Hercules, CA, USA) containing $5 \mathrm{ng}$ cDNA and $10 \mathrm{pM}$ of each primer. The cycling conditions were set as previously described [20]. The data were normalized to the geometric mean of housekeeping gene GAPDH or U6 small nuclear RNA expression and calculated as $2^{-}{ }^{\mathrm{CT}}$ method. Primers for real-time PCR were designed using Primer Premier 5 software. Sequences of the primers are summarized in Additional file 1: Table S1.

\section{Plasmids and transfection}

To generate a miR-224 expression vector, a 281 bp genomic fragment covering the region coding for pri-miR224 and its upstream and downstream regions was PCR amplified and cloned into the pLvthm vector (Addgene). The fullength of GSK3 3 3'-UTR is 4849 bp long and the SFRP2 3'-UTR is $876 \mathrm{bp}$ long. The miR-224 binding site in the GSK3 $\beta$ 3'-UTR is located at 4755 to $4762 \mathrm{bp}$, and 316 to $323 \mathrm{bp}$ in the SFRP2 3'-UTR. The region of the human GSK3 $\beta$ 3'-UTR from 4635 to 4825 bp and SFRP2 3'-UTR from 209 to $549 \mathrm{bp}$ were generated by PCR amplification and subcloned into the MluI/NheI sites of the pGL3-basic luciferase reporter plasmid (Promega). The miR-224 mimics, negative control and anti-miR-224 inhibitors were purchased from Genecopoeia (Genecopoeia Co. Ltd.) and transfected into CRC cells using Lipofectamine 2000 reagent (Invitrogen), according to the manufacturer's instructions. Two concentrations of miR224 mimics or anti-miR-224 inhibitors (20 and $50 \mathrm{nM}$ ) were applied. Also, the CDS of GSK3 $\beta$ was generated by PCR amplification and subcloned into the NheI/EcoRI sites of the pSin-EF2-puro plasmid, and the CDS of SFRP2 was generated by PCR amplification and subcloned into the SpeI/EcoRI sites of the pSin-EF2-puro plasmid. The primers used to generate above constructs are listed in Additional file 2: Table S2. The stable cell lines were established as previously described [26].

\section{Western blotting}

We performed western blot according to the previous study [21]. Protein lysates were prepared, subjected to SDS-PAGE, transferred onto PVDF membranes and blotted according to standard methods, using anti-GSK3 $\beta$, anti-phospho- $\beta$-catenin (Ser9), (Cell Signaling Technology), anti-CyclinD1, anti-c-Myc (Bioworld Technology, St. Louis Park, MN, USA)), anti-Ki-67 (Abcam, Cambridge, 
MA, USA), anti-MMP7, anti-SFRP2 (BD Biosciences, San Diego, CA, USA), anti- $\beta$-catenin (BD Biosciences, San Diego, CA, USA). Anti- $\alpha$-Tubulin monoclonal antibody (Sigma, St Louis, MO, USA) served as a loading control.

\section{Luciferase assays}

Cells $\left(8 \times 10^{4}\right)$ were seeded in triplicate in 24 -well plates and allowed to settle for $24 \mathrm{~h}$. Luciferase reporter plasmids (100 ng) or $100 \mathrm{ng}$ control luciferase plasmid plus $1 \mathrm{ng}$ pRL-TK Renilla plasmid (Promega) were transfected into colorectal cancer cells using Lipofectamine 2000 (Invitrogen). Luciferase and Renilla signals were determined $24 \mathrm{~h}$ after transfection using a Dual Luciferase Reporter Assay Kit (Promega) [27, 28].

\section{Soft-agar colony formation assay, three-dimensional morphogenesis assay, transwell assay and immunohistochemistry}

The miR-224 mimics, anti-miR-224 inhibitors, negative control oligos and GSK3 $\beta /$ SFRP2 plasmids were transiently transfected into CRC cells for the soft agar colonyformation assay, three-dimensional morphogenesis assay, transwell assay and immunohistochemistry, as previously described [21, 29].

\section{Xenograft model in nude mice}

For tumourigenesis assays, Xenograft tumors were generated by subcutaneous injection of stable cell lines. Animal experiments were conducted as previously described [20]. Details are as previously Supplementary Materials and Methods described [21]. All mice were obtained from the Animal Center of Southern Medical University, Guangzhou, China, and housed and maintained under specific pathogen-free conditions, and all experiments were approved by the Use Committee for Animal Care and performed in accordance with institutional guidelines. Tumor size was measured using a slide caliper and tumor volume was determined by the formula: $0.44 \times \mathrm{A} \times \mathrm{B}^{2}$, where A represents the diameter of the base of the tumor and $\mathrm{B}$ represents the corresponding perpendicular value.

\section{Statistical analysis}

All experiments were performed at least twice. Results are expressed as mean \pm S.E.M. where applicable. The two-tailed Student's $t$-test was used to compare the intergroup. Spearman's correlation analyses were used to analyze the relationship between miR-224 expression and target genes. Differences between groups were considered statistically significant at $p<0.05$. Analyses were done with SPSS 19.0 software (IBM, Armonk, NY, USA).

\section{Results}

MiR-224 activates the Wnt/ $\beta$-catenin signaling in CRC cells Previously, we found that miR-224 could promote cell proliferation by repressing PHLPP1 and PHLPP2 in CRC. Besides the activation of AKT signaling, we also observed that miR-224 can activated Wnt/ $\beta$-catenin signaling. The activity of $\mathrm{Wnt} / \beta$-catenin signaling pathway by TOP/FOP Luciferase assay was significantly increased in miR224-overexpressing CRC cells and reduced in miR-224inhibited CRC cells (Fig. 1a). Further, we carried out Western blot and real-time PCR to analyze the transcriptional downstream genes of $\mathrm{Wnt} / \beta$-catenin signaling. Figure $1 b$ and $c$ showed that overexpression of miR-224 significantly upregulated c-Myc, CyclinD1, MMP7 and the activity of $\beta$-catenin, while inhibition of miR-224 obviously downregualted c-Myc, CyclinD1, MMP7 and the activity of $\beta$-catenin. Moreover, immunofluorescence staining assay displayed that overexpression of miR-224 could evidently promote the nuclear localization of $\beta$-catenin (Fig. 1d).

\section{MiR-224 directly targets GSK3 $\beta$ and SFRP2}

In order to predict the putative miR-224 target genes, target prediction program (TargetScan) was applied. The results revealed that GSK3 $\beta$ and SFRP2 are two potential targets of miR-224. The 3'-UTR of GSK3 $\beta$ and SFRP2 mRNA contains a complementary site for the seed region of miR-224 (Fig. 2a). It has been reported that GSK3 $\beta$ and SFRP2 are key regulators of Wnt signaling by controlling the activity of the $\beta$-catenin/TCF transcription complex. Real-time PCR (Fig. 2b) and western blot (Fig. 2c) results showed that both the mRNA and protein levels of both GSK3 $\beta$ and SFRP2 were significantly downregulated in miR-224-overexpressing cells, whereas GSK3 $\beta$ and SFRP2 were upregulated after inhibition of miR-224 in CRC cells. Furthermore, we subcloned the wild-type and mutant fragments of GSK3 $\beta$ or SFRP2 3'-UTR fragment separately into the pGL3-basic luciferase reporter vectors. As showed in Fig. 2d, both wild-type GSK3 $\beta$ and SFRP2 reporter gene luciferase activity was reduced upon overexpression of miR-224 in both colorectal cancer cell lines, whereas inhibition of miR-224 increased wild-type GSK3 $\beta$ or SFRP2 luciferase activity.

MiR-224 promote migration and proliferation of CRC cells partly through inhibition of GSK3 $\beta$ and SFRP 2 in vitro GSK3 $\beta$ and SFRP2 are important effectors of numerous miRNAs in human cancers, so we need to further explore the biological effects of miR-224 on GSK3 $\beta$ and SFRP2 in a reverse logic. We adopted western blot assay to detected the role of miR-224 in CRC cells under overexpression of GSK3 $\beta$ and SFRP2 (Fig. 3a). Cell function assays displayed that upregulation of miR-224 revealed higher proliferation, migration and invasion capacity, 


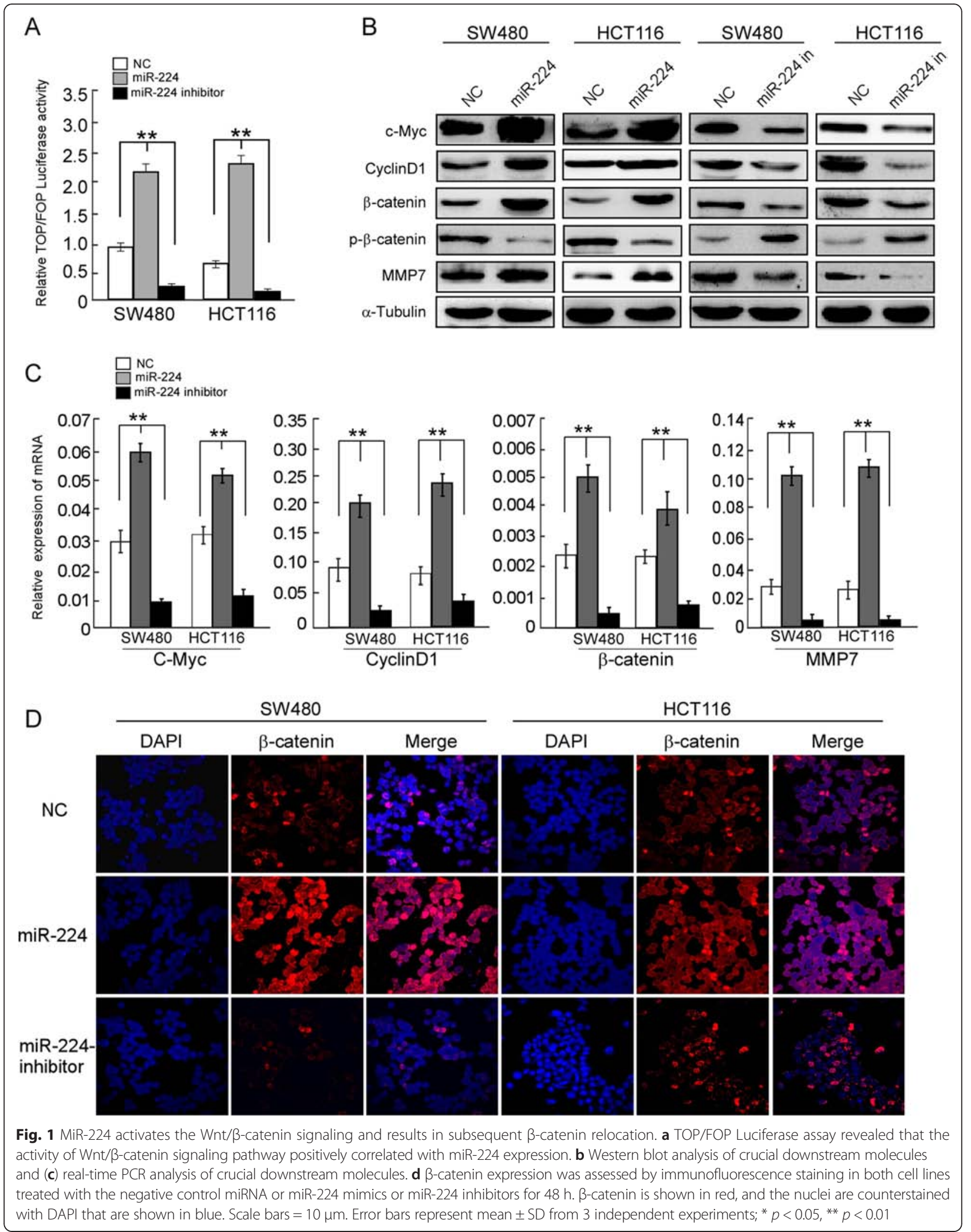



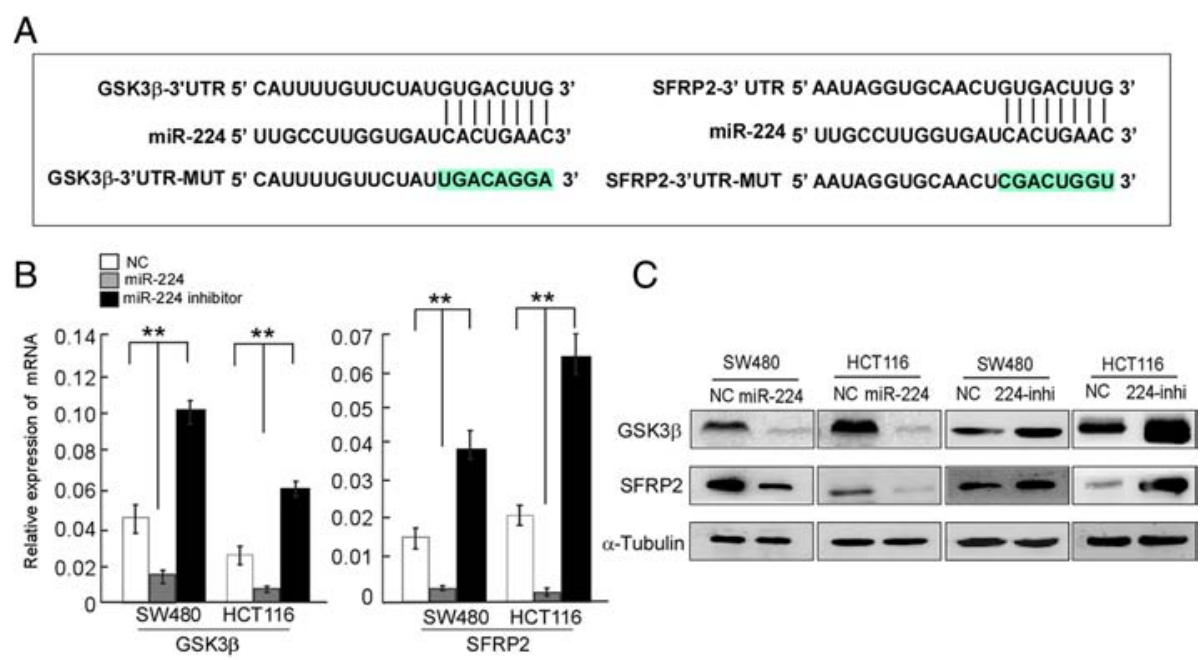

D
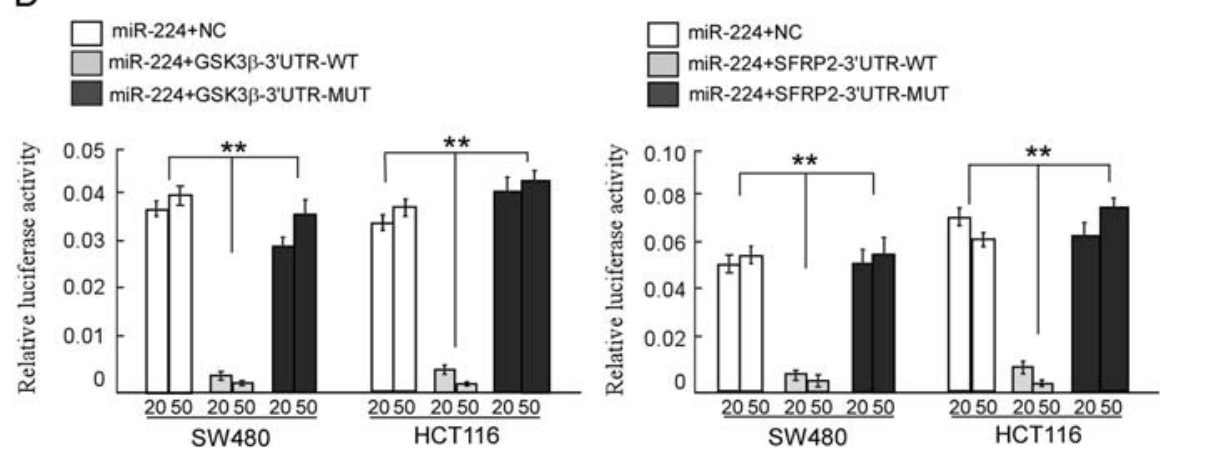

Fig. 2 MiR-224 could target GSK3 $\beta$ and SFRP2 in CRC. a Predicted miR-224 target sequences in the $3^{\prime}-U T R s$ of GSK3 3 or SFRP2, and their mutants containing altered nucleotides in the 3'-UTRs. b Real-time PCR analysis of GSK3 $\beta$ or SFRP2. $\mathbf{c}$ Western blot analysis of GSK3 $\beta$ or SFRP2. $\mathbf{d}$ Luciferase assay analyses of the indicated cells transfected with the indicated reporters with increasing amounts of miR-224 (20 and $50 \mathrm{nM}$ ). Error bars represent mean \pm SD from three independent experiments; ${ }^{*} p<0.05,{ }^{* *} p<0.01$

while ectopic up-regulated GSK3 $\beta$ and SFRP2 could partially reverse the influence of miR-224 on CRC cells growth, migration and invasion. Soft agar assays displayed that inhibition of miR-224 evidently reduced the growth rate of both colorectal cancer cell lines while overexpression of miR-224 promoted the growth rate of both colorectal cancer cell lines (Fig. 3b). Impact of miR-224 on cell migration (Fig. 3c) and invasion (Fig. 3d) across a Transwell chamber and three-dimensional morphogenesis assay (Fig. 3e) showed that inhibition of miR-224 supressed migration and invasion capacity of both colorectal cancer cell lines, while overexpression of miR-224 enhanced migration and invasion capacity of both colorectal cancer cell lines. Especially, compared with other cells, overexpression of miR-224 displayed a long spindle-shaped form with thin, long pseudopods, which occasionally resembled finger-like pseudopods that extended from the cell bodies (Fig. 3e). In addition, the results showed ectopic overexprssion of GSK3 $\beta$ and SFRP2 could partially reverse the influence of miR-224 on cell growth migration and invasion.
GSK3 $\beta$ and SFRP2 are the bona fide effector of miR-224 in vivo

To understand whether GSK3 $\beta$ and SFRP2 are involved in miR-224 mediated CRC tumorgenesis in vivo, we engineered SW480 cells to stably overexpress miR-224. The control cells, miR-224-overexpressing cells and the restored GSK3 $\beta$ and SFRP2 in miR-224-overexpressing cells were subcutaneously inoculated into nude mice separately. As shown in Fig. 4a and b, the tumors in the SW480/miR224 group grew more rapidly than the other group tumors, SW480/NC group and SW480/miR-224-GSK3 $\beta$ -SFRP2 group $(P<0.01)$. IHC staining (Fig. $4 \mathrm{c} / \mathrm{d})$ further confirmed that the tumors of the miR-224-overexpressing group displayed much higher Ki-67 indexes than the other two groups.

\section{Clinical data confirmed GSK3 $\beta$ or SFRP2 are the direct targets of miR-224}

To further verify the above observations, miR-224 directly targets GSK3 $\beta$ and SFRP2, could be supported by observations in human CRC. We first tested the expression of 


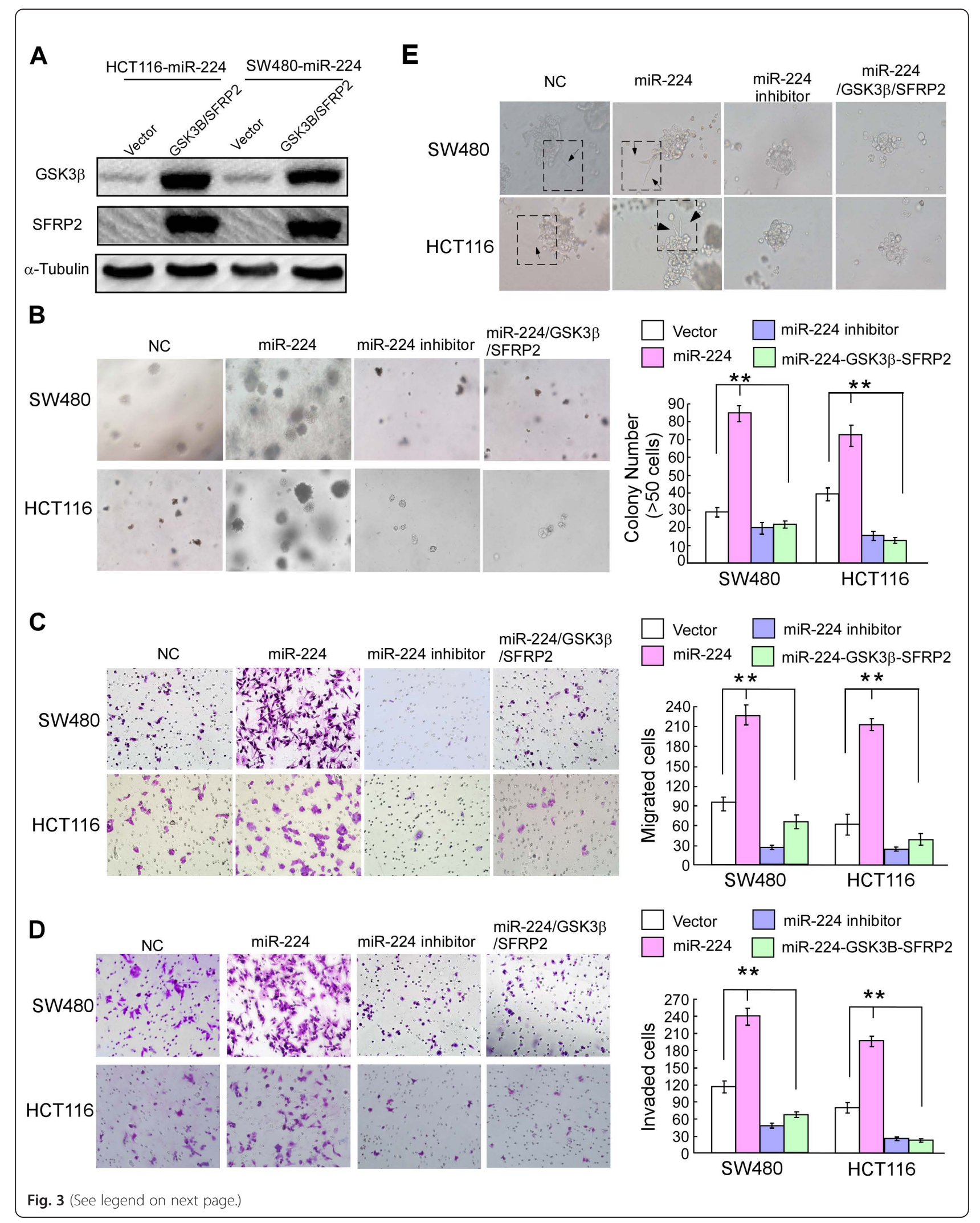


(See figure on previous page.)

Fig. 3 MiR-224 manipulates the colon cancer cells proliferation and migration partly through GSK3 $\beta$ and SFRP2. a Western blot analysis of GSK3 $\beta$ or SFRP2. b Soft agar assay. Representative micrographs are shown (left) and only cell colonies $>0.1 \mathrm{~mm}$ in diameter were counted (right). $\mathbf{c}$ Representative images (left) and quantification (right) of migrated cells across a Transwell chamber. $\mathbf{d}$ Representative images (left) and quantification (right) of invaded cells across a Transwell chamber. e Representative micrographs of indicated cultured cells at day 7 of culture in three-dimensional morphogenesis assay. Error bars represent mean \pm SD from 3 independent experiments; ${ }^{*} p<0.05,{ }^{* *} p<0.01$

A

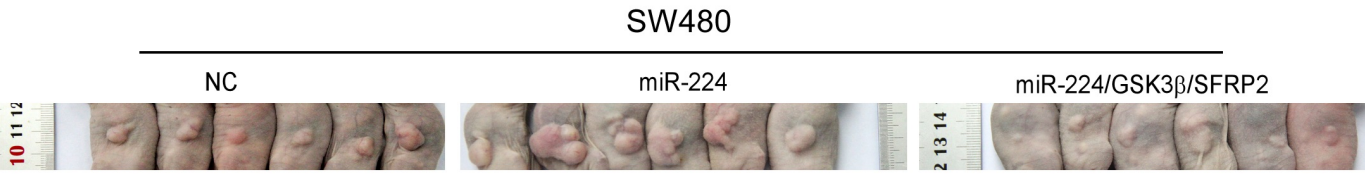

B
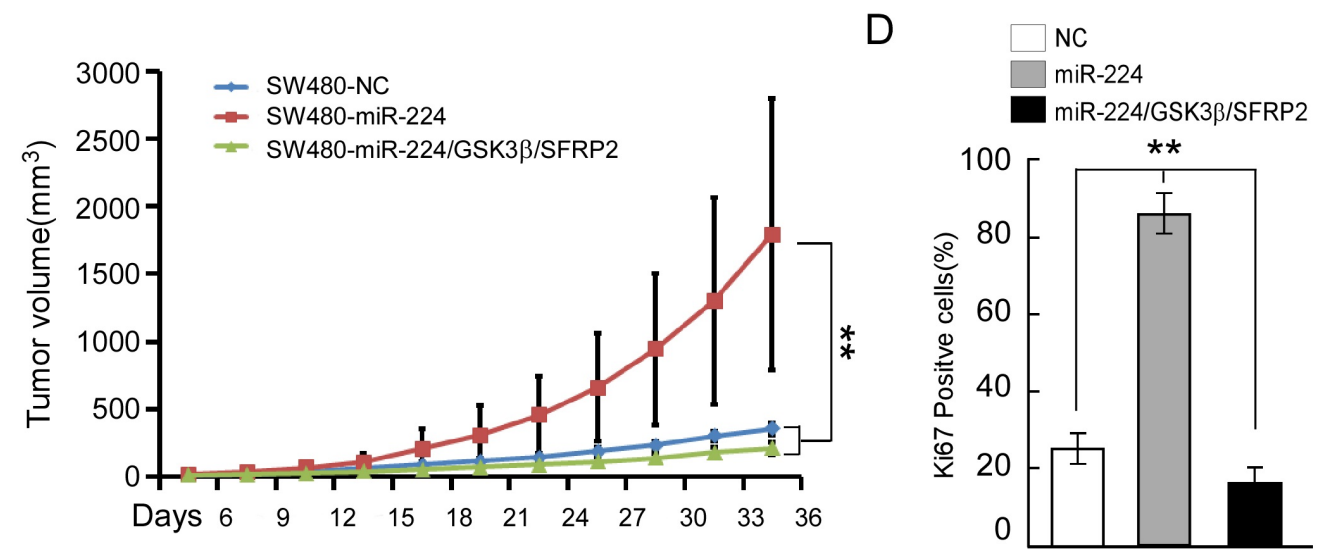

C

SW480

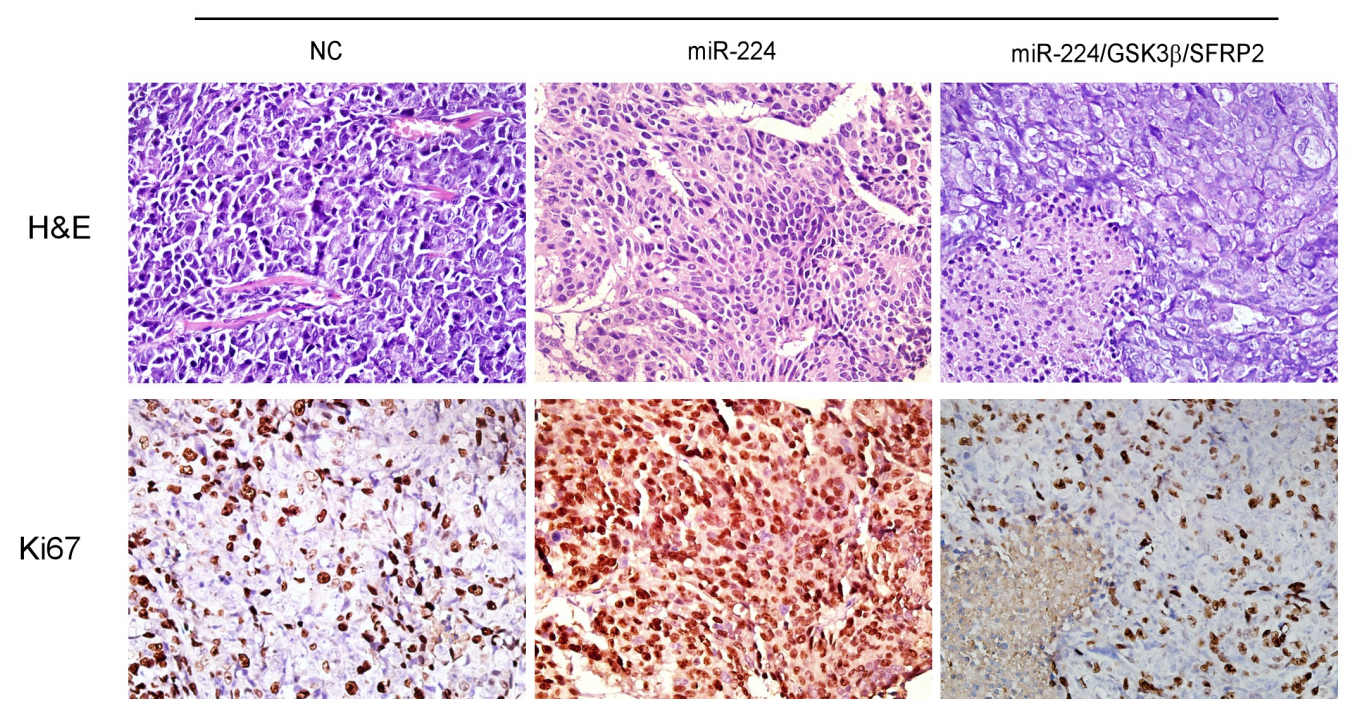

Fig. 4 GSK3 $\beta$ and SFRP2 are the bona fide effector of miR-224 in vivo. a Tumor xenograft model. Cells were injected into the hindlimbs of nude mice $(n=6)$. Representative images of the tumors are shown. $\mathbf{b}$ Tumor volumes were measured on the indicated days. Data points are presented as the mean tumor volume \pm SD. c Histopathology of xenograft tumors. The tumor sections were under H\&E staining and IHC staining using antibody against Ki-67. d The percentage of Ki67 positive cells. Error bars represent mean \pm SD from 3 independent experiments; ${ }^{*} p<0.05$, ${ }^{* *} p<0.01$ 


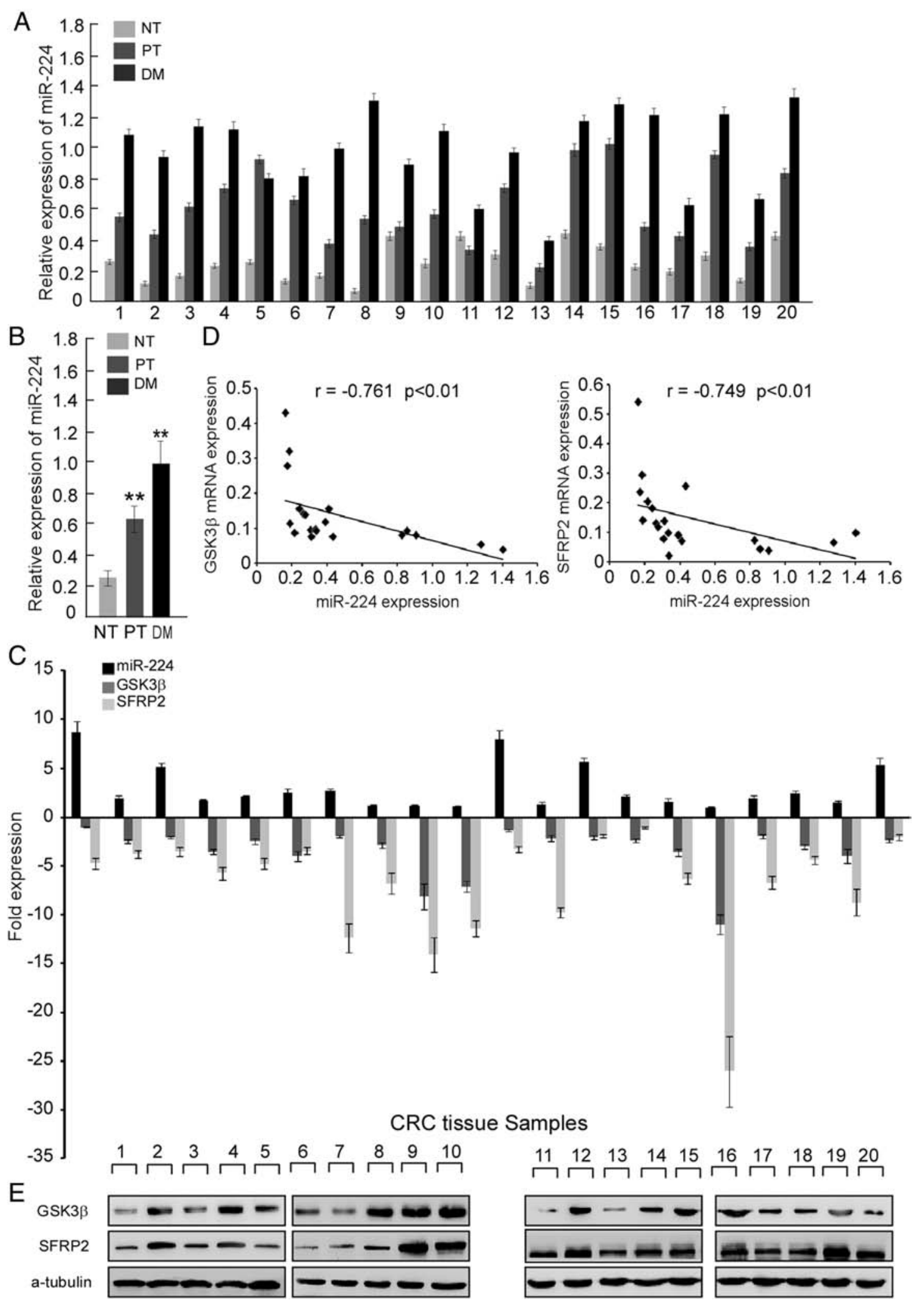

Fig. 5 (See legend on next page.) 
(See figure on previous page.)

Fig. 5 Clinical data confirmed GSK3 3 or SFRP2 are the direct targets of miR-224. a Real-time PCR analysis of miR-224 expression in 20 pairs of peri-cancerous normal tissues (NT), CRC primary tumor tissues (PT), and distantly metastasis tissues (liver, DM); miR-224 expression was normalized to U6. b Mean expression of miR-224 in the 20 pairs of peri-cancerous normal tissues (NT), CRC primary tumor (PT), and distantly metastasis (DM). c Real-time PCR analysis of miR-224, GSK3 $\beta$ and SFRP2 expression and (d) Spearman correlation analyses between relative miR-224 expression and relative mRNA expression levels of GSK3 $\beta$ and SFRP2 in 20 fresh human CRC samples. e Western blot analysis of GSK3 $\beta$ and SFRP2 in the 20 fresh human CRC samples; -Tubulin was used as loading control (lower panel). Error bars represent mean \pm SD from 3 independent experiments; ${ }^{*} p<0.05,{ }^{* *} p<0.01$

miR-224 by real-time PCR analysis in 20 pairs of distant metastasis (liver, DM), CRC primary tumor (PT), and peri-cancerous normal tissues (NT). The results (Fig. 5a and b) revealed that miR-224 was significantly overexpressed in DM and PT tissues than NT tissues $(p<0.01)$. Moreover, the expression levels of miR-224 were higher in DM than in PT tissues $(p<0.01)$. Then we analyzed 20 pairs of freshly CRC tissues and normal tissues to explore the relationship between miR-224 and GSK3 $\beta$ or SFRP2. Figure $5 \mathrm{c}$ revealed that miR-224 was up-regulated in CRC tissues while GSK3 $\beta$ or SFRP2 were down-regulated in CRC tissues. The 20 pairs Q-PCR data was attached in Additional file 3: Data S1. Spearman correlation analyses shows that miR-224 expression negatively correlated with the expressions of GSK3 $\beta(r=-0.761, p<0.01)$, SFRP2 $(r=-0.749, p<0.01)$ (Fig. $5 \mathrm{~d}$ ). Also, western blot analysis confirmed miR-224 expression negatively correlated with the expressions of GSK3 $\beta$ and SFRP2 (Fig. 5e). The above molecular link provides a significant clue for us to figure out the role of miR-224 in the process of CRC Wnt/ $\beta$-catenin signaling.

\section{Discussion}

MiRNAs are endogenous non-coding RNAs that are related to several key biological processes of tumor, such as tumor initiation, cell proliferation and metastasis which decrease gene expression through binding to the 3'-UTR of target mRNAs $[18,30,31]$. The Wnt/ $\beta$-catenin signaling pathway has been recognized to play a critical role in regulating oncogenesis and metastasis [17, 32, 33]. Notablely, many evidence approved aberrant activation of Wnt/ $\beta$-catenin signaling is a hallmark of colorectal tumorigenesis as well as in later stages of invasion and metastasis [2, 18, 34]. Meanwhile, accumulated evidence showed that miRNAs are crucial modulators of Wnt/ $\beta$-catenin signaling pathway [35-38]. In addition, recent studies demonstrated that miR-224 can promote cell invasion and proliferation in several human cancers [39-41], especially in CRC [21, 42], suggesting its function as an oncogene. However, no further explanations were carried out to illuminate the relationship between miR-224 and Wnt/ $\beta$-catenin signaling and the mechanism of miR-224induced CRC invasion. In this study, we demonstrated the role of miR-224 in activating $\mathrm{Wnt} / \beta$-catenin signaling, and caused the malignant of CRC.
To explore the impact of miR-224 on Wnt/ $\beta$-catenin signaling pathway, we tested the activity of $\mathrm{Wnt} / \beta$-catenin signaling pathway by performing TOP/FOP Luciferase assays. The $\mathrm{T}$ cell factor (TCF) activity was significantly increased in miR-224 -overexpressing CRC cells, but was decreased in miR-224-inhibited cells. Furthermore, downstream molecules of Wnt signaling and the activity of $\beta$ catenin were significantly positive correlated with miR-224. Furthermore, the results demonstrate that miR-224 could promote $\beta$-catenin translocate into nucleus.

To further clarify the functional mechanism by which miR-224 activates the Wnt/ $\beta$-catenin signaling cascade. By bioinformatics prediction (TargetScan) and functional analysis, we identified GSK3 $\beta$ and SFRP2 as direct downstream targets of miR-224. As a crucial member of Wnt/ $\beta$-catenin signaling modulators, GSK3 $\beta$ plays a central role in the degradation complex and directly depends on the phosphorylation level of $\beta$-catenin [43]. GSK3 $\beta$ knockdown promotes several kinds of cancer proliferation and metastasis by promoting $\beta$-catenin translocation into nucleus and upregulated oncogene snail expression to promote cancer cells metastasis [44, 45]. SFRP2 is a newly discovered Wnt signaling negative modulators by direct interaction with Wnts $[46,47]$. SFRP2 is also downregulated in colorectal cancer and is linked with the EMT as well as proliferation $[48,49]$. Collectively, these studies suggest that restoration of the expression or function of the GSK3 $\beta$ and SFRP2 may represent a potential novel therapeutic intervention strategy for CRC. However, precise details of the mechanisms which regulate GSK3 $\beta$ and SFRP2 need further investigation.

Our results confirmed that both GSK3 $\beta$ and SFRP2 were direct targets of miR-224. More specifically, we found that miR-224 significantly downregulated the expression of GSK3 $\beta$ and SFRP2 in CRC cells. Furthermore, we found that GSK3 $\beta$ and SFRP2 restoration could reverse the biological ability of enforced miR-224 expression in vitro and in xenograft models. Interestingly, we found that the miR-224 expression in distantly metastasis tissues was higher than primer tumor tissues and normal tissues by analysis of 20 pairs of clinical tissues. Finally, expression analyses of miR-224, GSK3 $\beta$ and SFRP2 in 20 clinical colorectal cancer tissues revealed significant negative correlations between miR-224 and the expression of GSK3 $\beta$ and SFRP2. All these results supported that miR-224 
promoted cell metastasis and proliferation through the Wnt/ $\beta$-catenin pathway.

\section{Conclusions}

In summary, this study demonstrates meaningful evidence expounding a new functional role of miR-224 in CRC. We showed that miR-224 has the ability to promote CRC cell growth and invasion, which are the basal behavior in CRC metastasis, through directly activating $\mathrm{Wnt} / \beta$-catenin signaling by targeting GSK3 $\beta$ and SFRP2. Also, restoring the expression of GSK3 $\beta$ and SFRP2 restrained miR-224induced aggressive phenotype of colorectal cancer cells. Furthermore, miR-224 expression is upregulated in colorectal cancer tumor samples and is inversely correlated with GSK3 $\beta$ and SFRP2. Our results discovered a new role of miR-224, modulating Wnt/ $\beta$-catenin signaling in CRC tumorgenesis, further indicating that miR-224 may serve as a diagnostic and prognostic biomarker for colorectal cancer.

\section{Additional files}

Additional file 1: Table S1. Primer Sequences Used for Real-time PCR (5' to $\left.3^{\prime}\right)$. (DOC $31 \mathrm{~kb}$ )

Additional file 2: Table S2. Primer sequences used for amplification and plasmid construction (5' to $\left.3^{\prime}\right)$. (DOC $30 \mathrm{~kb}$ )

Additional file 3: Data S1. mRNA expression of miR-224, GSK3ßand SFRP2 in 20 CRC tissues. (DOC $15 \mathrm{~kb}$ )

\section{Competing interests}

The authors declare no conflict of interest.

\section{Authors' contributions}

WTL and YQD designed the experiments; TTL, QHL, SYW, JJC, LQH, DLD and ZYX conducted experiments; LL, YYP and HLJ provided research materials and methods; TTL and QHL analysed data; and WTL and TTL wrote the manuscript. All authors read and approved the final manuscript.

\section{Acknowledgements}

This work was supported by the National Basic Research Program of China (973 program, nos. 2015CB554002 and 2010CB529403), the National Natural Science Foundation of China (NSFC)-Guangdong Joint Fund (U1201226), the Major Projects of the National Natural Science Foundation of China (no. 81090422), the National Natural Science Foundation of China (no. 81172055, 81472313, and 81472710), Guangdong Provincial Natural Science Foundation of China (no. 2014A030313283), National Science Foundation for Young Scientists of China (no. 81402375).

\section{Author details}

${ }^{1}$ Department of Pathology, Nanfang Hospital, Southern Medical University, Guangzhou 510515, Guangdong, China. ${ }^{2}$ Department of Pathology, School of Basic Medical Sciences, Southern Medical University, Guangzhou, Guangdong, China. ${ }^{3}$ State Key Laboratory of Oncology in Southern China, Department of Experimental, Guangzhou, Guangdong, China.

\section{Received: 9 October 2015 Accepted: 7 January 2016} (t)

\section{References}

1. Siegel R, Naishadham D, Jemal A. Cancer statistics, 2013. CA Cancer J Clin. 2013;63:11-30

2. Qi L, Sun B, Liu Z, Cheng R, Li Y, Zhao X. Wnt3a expression is associated with epithelial-mesenchymal transition and promotes colon cancer progression. J Exp Clin Cancer Res. 2014;33:107.
3. Tian XH, Hou WJ, Fang Y, Fan J, Tong H, Bai SL, et al. XAV939, a tankyrase 1 inhibitior, promotes cell apoptosis in neuroblastoma cell lines by inhibiting Wnt/beta-catenin signaling pathway. J Exp Clin Cancer Res. 2013;32:100.

4. Kawano Y, Kypta R. Secreted antagonists of the Wnt signalling pathway. J Cell Sci. 2003;116:2627-34.

5. Reed KR, Athineos D, Meniel VS, Wilkins JA, Ridgway RA, Burke ZD, et al. Bcatenin deficiency, but not Myc deletion, suppresses the immediate phenotypes of APC loss in the liver. Proc Natl Acad Sci U S A. 2008;105:18919-23.

6. Failor KL, Desyatnikov Y, Finger LA, Firestone GL. Glucocorticoid-induced degradation of glycogen synthase kinase-3 protein is triggered by serumand glucocorticoid-induced protein kinase and Akt signaling and controls beta-catenin dynamics and tight junction formation in mammary epithelial tumor cells. Mol Endocrinol. 2007:21:2403-15.

7. Del Valle-Perez B, Arques O, Vinyoles M, de Herreros AG, Dunach M Coordinated action of CK1 isoforms in canonical Wnt signaling. Mol Cell Biol. 2011;31:2877-88.

8. Su Y, Fu C, Ishikawa S, Stella A, Kojima M, Shitoh K, et al. APC is essential for targeting phosphorylated beta-catenin to the SCFbeta-TrCP ubiquitin ligase. Mol Cell. 2008;32:652-61.

9. Pronobis MI, Rusan NM, Peifer M. A novel GSK3-regulated APC: Axin interaction regulates Wnt signaling by driving a catalytic cycle of efficient betacatenin destruction. Elife. 2015;4:e08022.

10. Arce L, Yokoyama NN, Waterman ML. Diversity of LEF/TCF action in development and disease. Oncogene. 2006;25:7492-504.

11. Lu FI, Sun YH, Wei CY, Thisse C, Thisse B. Tissue-specific derepression of TCF/LEF controls the activity of the Wnt/beta-catenin pathway. Nat Commun. 2014;5:5368.

12. Fearon ER, Vogelstein B. A genetic model for colorectal tumorigenesis. Cell. 1990;61:759-67.

13. Dow LE, O'Rourke KP, Simon J, Tschaharganeh DF, van Es JH, Clevers H, et al. Apc restoration promotes cellular differentiation and reestablishes crypt homeostasis in colorectal cancer. Cell. 2015;161:1539-52.

14. Brabletz T, Jung A, Reu S, Porzner M, Hlubek F, Kunz-Schughart LA, et al. Variable beta-catenin expression in colorectal cancers indicates tumor progression driven by the tumor environment. Proc Natl Acad Sci U S A. 2001;98:10356-61.

15. Phelps RA, Chidester S, Dehghanizadeh S, Phelps J, Sandoval IT, Rai K, et al. A two-step model for colon adenoma initiation and progression caused by APC loss. Cell. 2009:137:623-34.

16. Paulmurugan R. MicroRNAs - a new generation molecular targets for treating cellular diseases. Theranostics. 2013;3:927-9.

17. Zhang GJ, Li JS, Zhou H, Xiao HX, Li Y, Zhou T. MicroRNA-106b promotes colorectal cancer cell migration and invasion by directly targeting DLC1. J Exp Clin Cancer Res. 2015;34:73.

18. Hwang WL, Jiang JK, Yang SH, Huang TS, Lan HY, Teng HW, et al. MicroRNA-146a directs the symmetric division of Snail-dominant colorectal cancer stem cells. Nat Cell Biol. 2014;16:268-80.

19. Fang Z, Tang J, Bai Y, Lin H, You H, Jin H, et al. Plasma levels of microRNA24, microRNA-320a, and microRNA-423-5p are potential biomarkers for colorectal carcinoma. J Exp Clin Cancer Res. 2015;34:86.

20. Liao WT, Ye YP, Zhang NJ, Li TT, Wang SY, Cui YM, et al. MicroRNA-30b functions as a tumour suppressor in human colorectal cancer by targeting KRAS, PIK3CD and BCL2. J Pathol. 2014;232:415-27.

21. Liao WT, Li TT, Wang ZG, Wang SY, He MR, Ye YP, et al. microRNA-224 promotes cell proliferation and tumor growth in human colorectal cancer by repressing PHLPP1 and PHLPP2. Clin Cancer Res. 2013;19:4662-72.

22. He TC, Sparks AB, Rago C, Hermeking H, Zawel L, da Costa LT, et al. Identification of C-MYC as a target of the APC pathway. Science. 1998;281:1509-12

23. Tang Y, Simoneau AR, Liao WX, Yi G, Hope C, Liu F, et al. WIF1, a Wnt pathway inhibitor, regulates SKP2 and c-myc expression leading to $\mathrm{G}$ arrest and growth inhibition of human invasive urinary bladder cancer cells. Mol Cancer Ther. 2009:8:458-68.

24. Tetsu O, McCormick F. Beta-catenin regulates expression of cyclin D1 in colon carcinoma cells. Nature. 1999:398:422-6.

25. Udhayakumar G, Jayanthi V, Devaraj N, Devaraj H. Interaction of MUC1 with beta-catenin modulates the Wnt target gene cyclinD1 in $\mathrm{H}$. pylori-induced gastric cancer. Mol Carcinog. 2007;46:807-17.

26. Song LB, Zeng MS, Liao WT, Zhang L, Mo HY, Liu WL, et al. Bmi-1 is a novel molecular marker of nasopharyngeal carcinoma progression and immortalizes primary human nasopharyngeal epithelial cells. Cancer Res. 2006;66:6225-32. 
27. Jiang J, Yu C, Chen M, Zhang H, Tian S, Sun C. Reduction of miR-29C enhances pancreatic cancer cell migration and stem cell-like phenotype. Oncotarget. 2015;6:2767-78.

28. Lu YX, Yuan L, Xue XL, Zhou M, Liu Y, Zhang C, et al. Regulation of colorectal carcinoma stemness, growth, and metastasis by an miR-200CSox2-negative feedback loop mechanism. Clin Cancer Res. 2014;20:2631-42.

29. Liao WT, Jiang D, Yuan J, Cui YM, Shi XW, Chen CM, et al. HOXB7 as a prognostic factor and mediator of colorectal cancer progression. Clin Cancer Res. 2011;17:3569-78.

30. Calin GA, Croce CM. MicroRNA signatures in human cancers. Nat Rev Cancer. 2006;6:857-66.

31. Song SJ, Poliseno L, Song MS, Ala U, Webster K, Ng C, et al. MicroRNAantagonism regulates breast cancer stemness and metastasis via TET-familydependent chromatin remodeling. Cell. 2013;154:311-24.

32. Zhang W, Zhang T, Jin R, Zhao H, Hu J, Feng B, et al. MicroRNA-301a promotes migration and invasion by targeting TGFBR2 in human colorectal cancer. J Exp Clin Cancer Res. 2014;33:113.

33. Qi J, Yu Y, Akilli Ozturk O, Holland JD, Besser D, Fritzmann J, et al. New Wnt/ beta-catenin target genes promote experimental metastasis and migration of colorectal cancer cells through different signals. Gut 2015. doi:10.1136/ gutjinl-2014-307900.

34. Rustgi AK. The genetics of hereditary colon cancer. Genes Dev. 2007:21:2525-38.

35. Yamada N, Noguchi S, Mori T, Naoe T, Maruo K, Akao Y. Tumor-suppressive microRNA-145 targets catenin delta-1 to regulate Wnt/beta-catenin signaling in human colon cancer cells. Cancer Lett. 2013;335:332-42.

36. Zhou AD, Diao LT, Xu H, Xiao ZD, Li JH, Zhou H, et al. beta-Catenin/LEF1 transactivates the microRNA-371-373 cluster that modulates the Wnt/betacatenin-signaling pathway. Oncogene. 2012;31:2968-78.

37. Ji S, Ye G, Zhang J, Wang L, Wang T, Wang Z, et al. miR-574-5p negatively regulates Qki6/7 to impact beta-catenin/Wnt signalling and the development of colorectal cancer. Gut. 2013;62:716-26.

38. Cai J, Guan H, Fang L, Yang Y, Zhu X, Yuan J, et al. MicroRNA-374a activates Wnt/beta-catenin signaling to promote breast cancer metastasis. J Clin Invest. 2013;123:566-79.

39. Huang L, Dai T, Lin X, Zhao X, Chen X, Wang C, et al. MicroRNA-224 targets RKIP to control cell invasion and expression of metastasis genes in human breast cancer cells. Biochem Biophys Res Commun. 2012;425:127-33.

40. Wang Y, Toh HC, Chow P, Chung AY, Meyers DJ, Cole PA, et al. MicroRNA224 is up-regulated in hepatocellular carcinoma through epigenetic mechanisms. FASEB J. 2012;26:3032-41.

41. Wang $Y$, Lee AT, Ma JZ, Wang J, Ren J, Yang $Y$, et al. Profiling microRNA expression in hepatocellular carcinoma reveals microRNA-224 up-regulation and apoptosis inhibitor-5 as a microRNA-224-specific target. J Biol Chem. 2008;283:13205-15.

42. Ling H, Pickard K, Ivan C, Isella C, Ikuo M, Mitter R, et al. The clinical and biological significance of MIR-224 expression in colorectal cancer metastasis. Gut. 2015. doi:10.1136/gutjnl-2015-309372

43. Taelman VF, Dobrowolski R, Plouhinec JL, Fuentealba LC, Vorwald PP, Gumper I, et al. Wht signaling requires sequestration of glycogen synthase kinase 3 inside multivesicular endosomes. Cell. 2010;143:1136-48.

44. Shakoori A, Ougolkov A, Yu ZW, Zhang B, Modarressi MH, Billadeau DD, et al. Deregulated GSK3beta activity in colorectal cancer: its association with tumor cell survival and proliferation. Biochem Biophys Res Commun. 2005:334:1365-73.

45. Grassilli E, Narloch R, Federzoni E, lanzano L, Pisano F, Giovannoni R, et al. Inhibition of GSK3B bypass drug resistance of p53-null colon carcinomas by enabling necroptosis in response to chemotherapy. Clin Cancer Res. 2013:19:3820-31.

46. Bhanot P, Brink M, Samos CH, Hsieh JC, Wang Y, Macke JP, et al. A new member of the frizzled family from Drosophila functions as a Wingless receptor. Nature. 1996;382:225-30.

47. Chung MT, Lai HC, Sytwu HK, Yan MD, Shih YL, Chang CC, et al. SFRP1 and SFRP2 suppress the transformation and invasion abilities of cervical cancer cells through Wnt signal pathway. Gynecol Oncol. 2009;112:646-53.

48. Vatandoost N, Ghanbari J, Mojaver M, Avan A, Ghayour-Mobarhan M, Nedaeinia R, et al. Early detection of colorectal cancer: from conventional methods to novel biomarkers. J Cancer Res Clin Oncol 2015;142:341-51.

49. Tang D, Liu J, Wang DR, Yu HF, Li YK, Zhang JQ. Diagnostic and prognostic value of the methylation status of secreted frizzled-related protein 2 in colorectal cancer. Clin Invest Med. 2011;34:E88-95.

\section{Submit your next manuscript to BioMed Central and we will help you at every step:}

- We accept pre-submission inquiries

- Our selector tool helps you to find the most relevant journal

- We provide round the clock customer support

- Convenient online submission

- Thorough peer review

- Inclusion in PubMed and all major indexing services

- Maximum visibility for your research

Submit your manuscript at www.biomedcentral.com/submit 